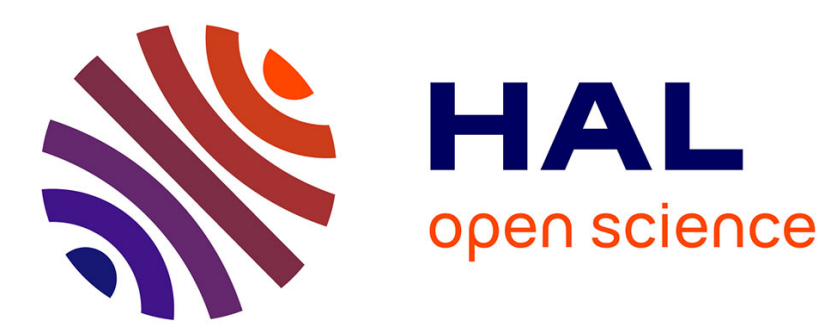

\title{
Oxidation of nanocrystalline aluminum by variable charge molecular dynamics
}

\author{
A. Perron, S. Garruchet, O. Politano, G. Aral, V. Vignal
}

\section{To cite this version:}

A. Perron, S. Garruchet, O. Politano, G. Aral, V. Vignal. Oxidation of nanocrystalline aluminum by variable charge molecular dynamics. Journal of Physics and Chemistry of Solids, 2010, 71 (2), pp.119. 10.1016/j.jpcs.2009.09.008 . hal-00609753

\section{HAL Id: hal-00609753 https://hal.science/hal-00609753}

Submitted on 20 Jul 2011

HAL is a multi-disciplinary open access archive for the deposit and dissemination of scientific research documents, whether they are published or not. The documents may come from teaching and research institutions in France or abroad, or from public or private research centers.
L'archive ouverte pluridisciplinaire HAL, est destinée au dépôt et à la diffusion de documents scientifiques de niveau recherche, publiés ou non, émanant des établissements d'enseignement et de recherche français ou étrangers, des laboratoires publics ou privés. 


\section{Author's Accepted Manuscript}

Oxidation of nanocrystalline aluminum by variable charge molecular dynamics
A. Perron, S. Garruchet, O. Politano, G. Aral, V. Vignal
PII:
S0022-3697(09)00263-7
DOI:
doi:10.1016/j.jpcs.2009.09.008
Reference:
PCS 5946

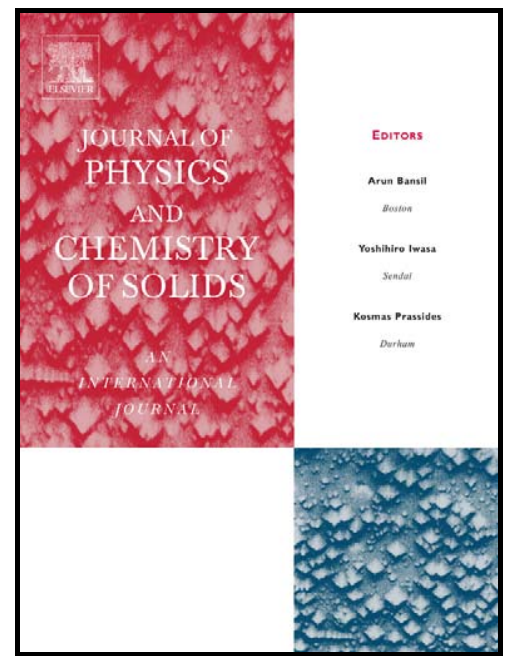

www.elsevier.com/locate/jpcs

To appear in: Journal of Physics and

Chemistry of Solids

Received date: $\quad 29$ May 2009

Revised date: $\quad 14$ September 2009

Accepted date: $\quad 15$ September 2009

Cite this article as: A. Perron, S. Garruchet, O. Politano, G. Aral and V. Vignal, Oxidation of nanocrystalline aluminum by variable charge molecular dynamics, Journal of Physics and Chemistry of Solids, doi:10.1016/j.jpcs.2009.09.008

This is a PDF file of an unedited manuscript that has been accepted for publication. As a service to our customers we are providing this early version of the manuscript. The manuscript will undergo copyediting, typesetting, and review of the resulting galley proof before it is published in its final citable form. Please note that during the production process errors may be discovered which could affect the content, and all legal disclaimers that apply to the journal pertain. 
Oxidation of nanocrystalline Aluminum by variable charge molecular dynamics

\section{Correspondig author :}

Olivier POLITANO

Département Interface et Réactivité dans les Matériaux

Institut Carnot de Bourgogne

UMR 5209 CNRS-Université de Bourgogne

9 AV. Alain Savary

BP 47870, 21078 DIJON Cedex, FRANCE

Tel: +33 (0)380396172 Fax: +33 (0)380 396132

e-mail : olivier.politano@u-bourgogne.fr

\section{Keywords :}

A. metals A. oxides A. thin films D. diffusion D. microstructure

\section{Manuscript Length :}

Text + references $=3978$ words

3 tables $=450$ words

7 figures $=1050$ words

Total $=5478$ words 


\title{
Oxidation of nanocrystalline Aluminum by variable charge molecular dynamics
}

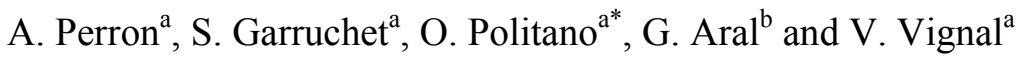 \\ ' ICB, UMR 5209CNRS, Université de Bourgogne,Dijon, France, politano@u-bourgogne.fr \\ ${ }^{b}$ Institut of Physics, Izmir Institut of Technology, Gulbahce Campus, TR-35437, Urla, Izmir, Turkey
}

\begin{abstract}
We investigate the oxidation of nanocrystalline aluminum surfaces using molecular dynamics (MD) simulations with the variable charge model that allows charge dynamically transfer among atoms. The interaction potential between atoms is described by the electrostatic plus $(\mathrm{Es}+)$ potential model, which is composed of an embedded atom method potential and an electrostatic term. The simulations were performed from 300 to $750 \mathrm{~K}$ on polycrystalline samples with a mean grain size of 5 nanometers. We mainly focused on the effect of the temperature parameter on the oxidation kinetic. The results show that, beyond a first linear regime, the kinetics follow a direct logarithmic law (governed by diffusion process) and tend to a limiting value corresponding to a thickness of $\sim 3 \mathrm{~nm}$. We also characterized at $600 \mathrm{~K}$ the effects of an external applied strain on the microstructure and the chemical composition of the oxide films formed at the surface. In particular, we obtained a partially crystalline oxide films for all temperature and we noticed a strong correlation between the degree of crystallinity of the oxide film and the oxidation temperature.
\end{abstract}

keywords : A. metals A. oxides A. thin films D. diffusion D. microstructure 


\section{Introduction}

Metal/oxide interfaces play critical roles in many applications, such as structural or functional materials in materials science, microelectronics, chemical and biomedical applications. In materials science for instance, the following technological materials are based on metal/oxide interfaces: functional ceramics with metals (cermets), oxide dispersion-strengthened alloys, oxide coatings on metals functioning as thermal barriers or natural corrosion protection layers. This is in particular the case of oxide passive films formed spontaneously on aluminum and aluminum alloys which protect the surface against further oxidation and corrosion. Also, because of their specific physical properties (i.e. large dielectric constant and height barrier for electron tunneling), aluminum oxides are promising candidate for gate dielectrics in the nanoscale CMOS technology, magnetic tunneling junctions, magnetic sensors, magnetic storage devices and solid-state memory, etc. [1-3]. At the same time, significant progress has been made to understand the combustion of nano-aluminum powders and the highly exothermic reaction of fine-grained aluminum particles (size $<100 \mathrm{~nm}$ ) with oxygen because of their use as potential additives to propellants for rockets [4-9]. For all these applications, it is crucial to understand the physico-chemical processes which control the reactivity of the metallic substrate and the thickness, morphology, chemical composition and microstructure of the oxide film [1].

The development of numerical studies of metal/oxides interfaces as well as oxide growth on the top of metals have required the development of the new class of interaction potential such as for example the variable charge method proposed by Streitz and Mintmire which is often referred as the $(\mathrm{Es}+)$ potential [10]. This last combines an embedded atom method (EAM) potential and an electrostatic term to model the metal-metal, oxygen-oxygen and metaloxygen interactions. The EAM contribution is predominant in the metallic region whereas the 
coulombic potential is used to model the ionic interactions within the oxide. It was initially fitted to model several properties of metallic aluminum (Al) and alpha alumina $\left(\alpha-\mathrm{Al}_{2} \mathrm{O}_{3}\right)$ which is the thermodynamically stable Al oxide. Later, Streitz and Mintmire also showed that the $(\mathrm{ES}+)$ potential was able to describe the gamma alumina $\left(\gamma-\mathrm{Al}_{2} \mathrm{O}_{3}\right)$ structure with a reasonable degree of accuracy [11]. This last point is of importance in the framework of the present study as high temperature oxidation of aluminum usually leads to the formation of transition alumina depending on the temperature.

Initially designed to simulate the properties of one metal (namely $\mathrm{Al}$ ) interacting with oxygen, the Streitz and Mintmire potential was recently extended/modified to simulate many metals (Ti, Zr, Fe, Ni, Co,...) and alloys [12-18]. It was used to study nanocrystalline metal-oxide properties [16-18] or processes involved in the oxidation of metallic substrates [12,13,19-22]. In this last case, the capability of the interatomic potential to determine the atomic charges on atoms due to its local environment was used to model the chemical reactions (bond formation and bond breakage) between a metal and an oxygen gas within a molecular dynamics simulation.

Recently, a new approach [23] was developed to solve one deficiency of the afore-mentioned variable charge models which were found to weakly describe the iono-covalent nature of the metal-oxygen bonding. For example, they lead to the underestimation by $30 \%$ of the calculated formation energy of an oxygen vacancy. This new generation of variable charge models incorporates new physics through a tight binding analytical model [24] and gave very satisfactory results for $\mathrm{ZrO}_{2}$ and $\mathrm{TiO}_{2}$ polymorphs. It looks very promising for the development of the future simulation of metal/oxyde systems. 
Oxidation of Al nanoclusters [19,20] or single-crystal surfaces of Al [21,22] for pressure ranging from 10 to 40 times the normal state were studied by variable charge molecular dynamics (VCMD) approaches. Under their oxidation conditions, these works clearly characterized the formation of an amorphous oxide layer. They reported a growth mechanism proceeding by both anionic and cationic diffusion and a direct logarithm relationship for the oxidation kinetic. Note that these VCMD simulations never permit to characterize the formation of a well crystalline oxide film.

On the other hand, experimental investigations on the high temperature oxidation of pure aluminum surfaces are difficult to perform due to the very high reactivity of $\mathrm{Al}$ with $\mathrm{O}$ and the presence of the native protective alumina scale. Surface preparation under high vacuum conditions is required and in-situ experimental techniques have to be conducted under very low oxidation pressure. Many experiments on bulk aluminum surfaces were developed by Jeurgens et al. with XPS and Auger spectroscopy. These studies were performed at very low oxidation pressure $\left(\sim 10^{-4} \mathrm{~Pa}\right)$ and mainly focused on the reaction kinetic, the composition and the structure of the alumina scale as a function of the temperature. That is i) at low temperatures $\left(\mathrm{T}<573 \mathrm{~K}\right.$ ), an amorphous and Al-deficient (as compared to $\gamma-\mathrm{Al}_{2} \mathrm{O}_{3}$ ) thin oxide film $(<5 \mathrm{~nm})$ is formed; ii) at higher temperatures $(\mathrm{T} \geq 673 \mathrm{~K})$, during the initial fast oxidation stage an Al-enriched amorphous oxide film is obtained and during the second slow oxidation stage the films gradually reach the stoechiometric composition and the crystalline structure of $\gamma-\mathrm{Al}_{2} \mathrm{O}_{3}[25-29]$.

In the present approach, we studied the oxidation under a constant molecular oxygen density (1 atm) of a polycrystalline $\mathrm{Al}$ substrate with a mean grain size of $5 \mathrm{~nm}$. We focused on the relation between the growth kinetics and the evolution of the chemical composition, by studying the structure of the developing oxide scale. In order to compare with the existing 
experimental results of Jeurgens et al., we used the same range of oxidation temperature (i.e., $300,600$ and $750 \mathrm{~K})$. Moreover, to highlight the influence of an applied strain on the oxidation mechanisms, one atomistic system was oxidized at $600 \mathrm{~K}$ after an uniaxial deformation $(+7 \%)$.

\section{Computational Methods}

We used the variable charge molecular dynamics method (VCMD) originally proposed by Streitz and Mintmire for Al-O systems [10]. In this formalism, the interatomic potential is a sum of the electrostatic and Finnis-Sinclair embedded-atom potentials and allows the atomic charges to vary dynamically in response to changes in the local environment of the atoms. The variable-charge approach determines atomic charges at each molecular dynamic step in such a way that the electrostatic potential energy is minimized, with the charge-neutrality constraint, i.e. the sum of the atomic charges is equal to zero. This condition is equivalent to the electronegativity equalization principle which requires that each atoms, aluminum (Al) and oxygen $(\mathrm{O})$, have an equal chemical potential.

The VCMD code used in this approach is developed by the "Collaboratory for Advanced Computing and Simulations" group at the University of Southern California [20]. It is highly parallel and allows to simulate million atoms metal-oxide systems. To speedup calculations, state of the art techniques are implemented: multiple time steps, multilevel preconditioned conjugate gradient method, fast multipole method and domain decomposition approach are used to implement the MD algorithm on parallel architectures [30-32].

The initial Al polycrystalline sample is a cube of size $10.256 \mathrm{~nm}$ containing 62932 atoms. The bulk polycrystalline system was created at $0 \mathrm{~K}$ by using a procedure analogous to the one 
used to obtain Voronoi cells (Fig. 1a). It was then thermalized by successive jumps of 50K until the desired temperature by using Noose-Hoover thermostat chain [33]. The slab geometry is then created by incorporating in the simulation box two vacuum slabs along the Z-direction while periodic boundary conditions are imposed along $\mathrm{X}$ and $\mathrm{Y}$ axis. For more details about the sample preparation procedure, the reader should refer to [34]. The final dimension of the simulation box is $\mathrm{Z}=15 \mathrm{~nm}$ and $\mathrm{X}=\mathrm{Y}=10.256 \mathrm{~nm}$ (Fig. 1b). Our MD simulations were performed by using a constant oxygen molecular density equal to the normal state $\mathrm{P}^{0}(1 \mathrm{~atm})$ above the $\mathrm{Al}$ polycrystalline surface. Every MD steps, the number of oxygen atoms present in the gas is examined and if this number is less than the imposed value, then new oxygen molecules (with a velocity equal to the oxidation temperature) are randomly introduced into the region above the $\mathrm{Al}$ surface in order to maintain the molecular oxygen density constant.

During the oxidation stage, only the $\mathrm{Al}$ atoms belonging to the lower $0.7 \mathrm{~nm}$ part of the polycrystalline substrate (Fig. 1b) were kept thermalized by using the thermostat. The constrain on the other $\mathrm{Al}$ atoms was removed and their kinetic energy (temperature) was free to evolve during all the oxidation process [35].

We integrated the equation of motions by using a multiple time step algorithm in which the MD time step is $\mathrm{dt}=2 \mathrm{fs}$ for short-range forces and $\mathrm{dt}=5 \mathrm{fs}$ for long-range forces. As the calculation of the charges is the most consuming part of VCMD, the local atomic charges are only calculated every 100th time steps. That is, after their updates the charges are kept constants during the following 99 steps to compute the forces and energies. A cutoff radius of 0.6nm was used to compute the Finnis-Sinclair potential. 
The strain samples were created by following a procedure which gave satisfactory results to study the multilayer surface relaxation of Al single-crystals [36] or the formation of surface roughness on strained polycrystalline $\mathrm{Al}$ substrates [34]. It consists of a direct deformation of the sample to the desire length. That is, we rescaled instantaneously the positions of the atoms along the Y-direction in order to obtain the required strain. The sample was then relaxed during $50 \mathrm{ps}$.

\section{Results and discussions}

\subsection{Kinetic law}

The kinetic curves obtained for all systems (unstrained : 300, 600 and $750 \mathrm{~K}$; strained : 600K) are plotted on Fig. 2. In this figure, the y-axis represents the evolution of the number of oxygen atoms introduced into the simulation box per unit surface area $\left(\mathrm{nm}^{2}\right)$. It can be assimilated to the variation of sample weight measured experimentally (Fig. 2a). The thickness of the oxide film is determined by calculating the difference between the mean position in the Z-direction of the ten highest $\mathrm{Al}$ atoms (near the gas/oxide interface) and the ten deepest oxygen atoms (at the metal/oxide interface). As one can notice, Fig. 2a and Fig. $2 \mathrm{~b}$ are similar to the classical representations obtained during high temperature oxidation experiments: sample weight gain/loss and film thickness evolution.

The kinetic curves presented on Fig. 2a show and identical behaviors for all oxidizing conditions. They can be divided into two parts: a first linear law followed by a direct logarithmic relationship. According to the oxidation theory and heterogeneous kinetics [3740], during the linear part the interfacial processes (dissociation of oxygen molecules, sorption of oxygen atoms, Al-O reaction) are predominant. Indeed, at the beginning of the oxidation, the oxygen atoms react directly with the Al substrate and the rate of this reaction 
governs the global kinetic. As presented on Fig. 2a, the linear law is available until around $1 \mathrm{~ns}$ of oxidation and corresponds to an oxide thickness of $\sim 1.5 \mathrm{~nm}$ (Fig. 2b). After this point, the oxygen atoms do not have direct access to the Al substrate but have first to cross the oxide film which acts as a barrier. So, this second kinetic part of the oxidation is controlled by diffusion of atomic species (oxygen and aluminum) through the film.

As two different processes occur during oxidation, we analyzed the kinetic curves by using a comprehensive law combining linear and logarithmic terms:

$$
N / S=K_{l} t+K_{\log } \log (D t+E) \quad \text { Eq. } 1
$$

In this expression, $t$ is the oxidation time, $N / \mathrm{S}$ is the number of oxygen atoms per unit area in the oxide film, $K_{l}$ and $K_{l o g}$ respectively the linear and logarithmic constants. $D$ and $E$ are mathematical parameters. Such combination of kinetic laws is rather standard when different processes occur during oxidation (the best example is the well known linear-parabolic relationship) and is detailed in textbooks on high temperature oxidations [37-40].

The numerical fitting of the kinetic curves by using Eq. 1 is reported on Fig. 3. We can observe an excellent fit of the oxidation kinetic by the comprehensive law: for low values of $N$, the linear law is predominant and then, with increasing $N$, the logarithmic law becomes majority. The parameters obtained from the numerical fitting are given in Table I. As one can notice, $\mathrm{K}_{1}$ which is the slope of the linear part remains almost constant for all oxidizing conditions. Therefore, sorption phenomena of oxygen are not modified by oxidation temperature or applied strain. On the other hand, $\mathrm{K}_{\log }$ increases with temperature and applied strain. Therefore, the diffusion of atomic species is facilitated by increasing the motion of atoms (temperature) and the inter-atomic distances (deformation). The activation energy, which can be deduced from the Arrhenius plots $\left(\ln \left(K_{\log }\right)\right.$ versus $\left.1 / T\right)$, was estimated at $1.3 \mathrm{~kJ} . \mathrm{mol}^{-1}$. This value is rather low compared to experimental results ranging from 9.5 to 
$238 \mathrm{~kJ} . \mathrm{mol}^{-1}$ for the oxidation of bulk Al or nano-particles ( $\left.\sim 50 \mathrm{~nm}\right)$ [7-9]. This difference might be explained by the very high reactivity of our samples induced by their small nanocrystalline microstructure (5nm grains), their total purity and the absence of a protective alumina scale at the surface of the sample. Finally, we note that the growth processes proceed almost exclusively by anionic migration (internal movement of oxygen anions through the oxide to the metal substrate).

The presence of the two kinetic regimes is corroborated by previous studies from Hasnaoui et al. on the oxidation of single-crystal Al surfaces. Indeed, these authors mentioned a short "transition" initial stage before the direct logarithmic law [21, 22]. Based on the present work, we are now able to conclude that the "transition" stage observed by Hasnaoui et al. was linear and governed by interfacial processes.

Concerning the oxide film thickness represented on Fig. 2b, we can observe an increase with the temperature until $\sim 3 \mathrm{~nm}$. This agrees well with the value of $5 \mathrm{~nm}$ reported by Jeurgens $e t$ al. with in-situ XPS and Auger spectroscopy [27]. Furthermore, small variations of thickness are observed after $1 \mathrm{~ns}$ for 600 and $750 \mathrm{~K}$. We observed a layer by layer growth mode for the oxide film at $300 \mathrm{~K}$. At higher temperature, the growth of the oxide is less uniform and leads to the fluctuations observed on Fig. 2b. Furthermore, microstructural changes of the oxide film can also produce this behavior. This last will be developed in the next section.

\subsection{Chemical composition}

As suggested above, the morphology and composition of the oxide films seems to vary with the temperature. To clarify the changes in composition, the fractions of aluminum, oxygen atoms and the various atomic densities have been calculated at the end of each oxidation. In order to avoid any spurious effect due to the interfaces which are too 
concentrated in aluminum or oxygen atoms, the calculations are performed between from $0.5 \mathrm{~nm}$ under the oxide/gas limit to $0.5 \mathrm{~nm}$ above the substrate/oxide limit. It corresponds to the middle part of the oxide film. The obtained values are reported in Table II and are discussed below.

Concerning the temperature: an increase of the aluminum atomic fraction in the oxide film is observed between 300 and $600 \mathrm{~K}$ (and consequently a proportional decrease of the oxygen fraction). Moreover, the $\mathrm{Al}$ atomic density decreases slightly with temperature whereas the $\mathrm{O}$ atomic density decreases strongly. As a consequence, the total density is decreasing between 300 and $600 \mathrm{~K}$. To resume, the increase of the oxidation temperature induces an increase of

the kinetic law and produces oxide films which are less dense and enriched in Al. Concerning the oxide film formed at $750 \mathrm{~K}$, the composition is similar to the one formed at $600 \mathrm{~K}$ but the density is different. It indicates that the microstructure changed between 600 and $750 \mathrm{~K}$. This point will be studied in more detail afterwards.

Concerning the applied strain $(+7 \%)$ : we noticed a slight increase of the $\mathrm{O}$ fraction and a strong increase of the $\mathrm{O}$ atomic density in the oxide film. To our point of view, these observations are due to the increase of the inter-atomic distances (Al-Al) which facilitates the insertion of $\mathrm{O}$ atoms in the substrate.

\subsection{Microstructure characterizations}

The temperature of the oxide film was computed as a function of time and is shown on Fig. 4. First, we observed a slight decrease of the temperature until the oxide scale cover completely the surface. After this very short transition regime, a great increase of temperature in the oxide is observed until $\sim 1.5 \mathrm{~ns}$. This phenomenon corresponds to the linear kinetic law determined previously (sorption process). After $1.5 \mathrm{~ns}$, which corresponds to the beginning of 
the logarithmic kinetic law (diffusion processes), the temperature of the oxide films reaches a maximum and then decreases very slowly with time. So, the evolution of the oxide temperature can be associated to the number of oxygen consumed. The oxidation reaction of $\mathrm{Al}$ is highly exothermic $\left(-1675 \mathrm{~kJ}^{\mathrm{mol}}{ }^{-1}\right)$ and, therefore, leads to a great increase of the oxide film temperature (included between 1000 and 2 000K). These high temperatures will favor the formation of crystalline $\mathrm{Al}_{2} \mathrm{O}_{3}$ structures as it increases the atomic motion/rearrangement in the films.

Pair distribution functions (PDF) for the Al-O bonds have been calculated in the middle part of the oxide films in order to characterize their microstructure. As presented in Fig. 5, many peaks are observed on the PDF and indicate the presence of long range order (a partially crystalline structure). But, no clear difference can be seen between the different curves. Moreover, one cannot determine the crystalline microstructure of the films from Fig. 5. A second step consists in calculating the environment of each atom by applying a common neighbor analysis on $\mathrm{Al}$ and $\mathrm{O}$ atoms $[41,42]$. The crystallographic structure of the thermodynamically stable alumina $\left(\alpha-\mathrm{Al}_{2} \mathrm{O}_{3}\right)$ is based on an hexagonal network of $\mathrm{O}$ and $\mathrm{Al}$ atoms [43]. Therefore, as a first approach we used the percentage of oxygen atoms located in hexagonal compact position (hep) within the oxide as a criteria to characterize the cristallinity of the film formed at the Al surface. The results are reported Table III. As one can see, the percentage of $\mathrm{O}$ in hep positions increases with temperature and also by applying a strain on the metallic substrate. This last highlights an increase of the degree of crystallinity from $\sim 32 \%$ at $300 \mathrm{~K}$ to $\sim 43 \%$ at $750 \mathrm{~K}$. Finally, the change in microstructure between 600 and $750 \mathrm{~K}$ suggested previously is confirmed. However, many transition alumina exist $-\gamma, \eta$ (cubic), $\theta$, $\theta^{\prime}, \theta^{\prime}, \lambda$ (monoclinic), $\delta-\mathrm{Al}_{2} \mathrm{O}_{3}$ (tetragonal or orthorhombic), $\alpha$ (trigonal), $\kappa$ (orthorhombic) , $\chi$ (hexagonal) - and the present study did not allowed us to determine which alumina polymorphs is present. In a forthcoming study, a more extended quantification of the ratios of 
tetrahedral $\mathrm{AlO}_{4}$ and octahedral $\mathrm{AlO}_{6}$ units will certainly help us to determine which alumina polymorph is formed during the simulation.

Concerning the polycrystalline microstructure, we did not observed a significant difference of reactivity between the $\mathrm{Al}$ atoms located in grains or in grains boundaries. Also, no preferential diffusion of the oxygen ions was observed at the grain boundaries.

\section{Conclusion}

We performed VCMD simulations on the oxidation of nanocrystalline aluminum between 300 and $750 \mathrm{~K}$. The influence of an external applied strain was also studied at $600 \mathrm{~K}$. This last permit us to obtain the corresponding kinetic curves and the formation of an thin oxide film which was analyzed with a common neighbor analysis and with pair distribution functions. The kinetic curves show the formation of a film with a limited thickness of about $3 \mathrm{~nm}$. Those curves can be divided in two regimes: a linear and a logarithmic. According to heterogeneous kinetics, these two regimes are governed by interfacial processes and by diffusion respectively. A comprehensive kinetic relationship permit us to compute the linear and a logarithmic constants. The linear constant was found to be independent of the temperature and the applied strain. At the opposite, the logarithmic constant, related motion of the atoms in the oxide scale, increases with both temperature and strain. Also, an increased of the degree of crystallinity within the oxide was observed with temperature and strains. We did not observed any preferential diffusion at the grains boundaries in the polycrystalline substrate.

Moreover, it is important to note that previous MD studies on single-crystal aluminum samples only reported the formation of amorphous alumina films. Here, we obtained the formation of a partially crystalline structure ( $42 \%$ of $\mathrm{O}$ atoms in hep positions at $750 \mathrm{~K})$. To 
our opinion, this might be related the lower oxygen pressure $(\mathrm{P}=1 \mathrm{~atm})$ used in the present approach as well as to the use of a large surface area which reduce the border effects. Also the kinetic factor is crucial and in order to leave the atoms reorganize to obtain a well crystalline oxide, we will surely have to simulate much longer times.

\section{Acknowledgments}

The authors want to thanks P. Vashishta, A. Nakano and R. Kalia for fruitful discussions.

This work has been partially performed under the HPC-EUROPA (RII3-CT-2003-506079) with the support of the European Community-Research Infrastructure Action under the FP6 "structuring the European Research Area Progamme". Part of computations have been carried out at the CRI-CCUB, IDRIS and ULAKBIM high performance computing center. 


\section{References}

1. J.M. De Teresa, A. Barthelemy, A. Fert et al., Science 286 (1999) 507.

2. E.S. Snow, P.M. Campbell, R.W. Rendell, et al., Semicond. Sci. Tech. 13 (1998) A75.

3. A.T.M. van Gogh, S.J. van der Molen, J.W.J. Kerssemakers et al., Appl. Phys. Lett. 77 (2000) 815.

4. A. Rai, K. Park, L. Zhou et al., Combust. Theor. Model. 10 (2006) 843.

5. A.L. Ramaswamy, P. Kaste, Energetic Materials 23 (2005) 1.

6. S. Alavi, J.W. Mintmire, D.L. Thompson, J. Phys. Chem. 109 (2005) 209.

7. J.M. Aaron, H.M. Chanb, M.P.Harmer et al., J. Eur. Ceram. Soc. 25 (2005) 3413.

8. K. Park, D. Lee, A. Rai, et al., J. Phys. Chem. B, 109 (2005) 7290.

9. F.H. Lu, H.D. Tsai, Y.C. Chieh, Thin Solid Films 516 (2008) 1871.

10. F.H. Streitz and J.W. Mintmire, Phys. Rev. B, 50 (1994) 11996.

11. F.H. Streitz and J.W. Mintmire, Phys. Rev. B, 60 (1999) 773.

12. X.W. Zhou and H.N.G. Wadley, J.S. Filhol et al., Phys. Rev. B, 69 (2004) 035402.

13. X.W. Zhou and H.N.G. Wadley, J. Phys. : Condens. Matter, 17 (2005) 3619.

14. S. Ogata, H. Lyetomi, K. Tsuruta et al., J. Appl. Phys., 86 (1999) 3036.

15. A. Hallil, R. Tétot, F. Berthier et al., Phys. Rev. B, 73 (2006) 165406.

16. V. Tomar and M. Zhou, Phys. Rev. B, 73 (2006) 174116.

17. A. Elsener, O. Politano, P.M. Derlet et al., Modelling Simul. Mater. Sci. Eng. 16 (2008) 025006 .

18. A. Elsener, O. Politano, P.M. Derlet et al., Acta Materialia 57 (2009) 1988.

19. T. Campbell, R.K. Kalia, A. Nakano et al., Phys. Rev. Lett., 82 (1999) 4866.

20. T.J. Campbell, G. Aral, S. Ogata et al., Phys. Rev. B 71 (2005) 205413.

21. A. Hasnaoui, O. Politano, J.M. Salazar et al., Surf. Sci. 579 (2005) 47.

22. A. Hasnaoui, O. Politano, J.M. Salazar et al., Phys. Rev. B 73 (2006) 035427.

23. R. Tétot, A. Hallil, J. Creuze et al., EPL, 83 (2008) 40001.

24. J. Goniaski and C. Noguera, Surf. Sci., 319 (1994) 81. 
25. L.P.H. Jeurgens, W.G. Sloof, F.D. Tichelaar et al., Surf. Sci. 506 (2002) 313.

26. L.P.H. Jeurgens, W.G. Sloof, F.D. Tichelaar et al., Thin Solid Films 418 (2002) 89.

27. L.P.H. Jeurgens, W.G. Sloof, F.D. Tichelaar et al., J. Appl. Phys. 92 (2002) 1649.

28. P.C. Snijders, L.P.H. Jeurgens, W.G. Sloof, Surf. Sci. 496 (2002) 97.

29. P.C. Snijders, L.P.H. Jeurgens, W.G. Sloof, Surf. Sci. 589 (2005) 98.

30. M. Tuckerman, B. J. Berne, and G. L. Martyna, J. Chem. Phys. 97 (1992) 1990.

31. A. Nakano, Comput. Phys. Commun. 104 (1997) 59.

32. L. Greengard and V. Rokhlin, J. Comp. Phys. 73 (1987) 325.

33. D. Frenkel and B. Smith, Understanding Molecular Simulation (San Diego : Academic Press, 2002).

34. A. Perron, O. Politano and V. Vignal, Phil. Mag. 87 (2007) 129.

35. A. Perron, Apport de la dynamique moléculaire et de techniques expérimentales à une échelle locale pour l'étude de surfaces d'aluminium déformées et/ou oxydées (Thèse de doctorat - Université de Bourgogne, 2008).

36 O. Politano, S. Garruchet, J.M. Salazar, Mat. Sci. Eng. A, 387-389 (2004) 749.

37. N. Birks, G. H. Meier and Frederick S. Pettit, Introduction to the high-temperature oxidation of metals, 2nd ed (Cambridge University Press, 2006)

38. Pierre Sarrazin, Alain Galerie, Jacques Fouletier and Hugh Evans, Mechanisms of High Temperature Corrosion: A Kinetic Approach (Trans Tech Publications Ltd., 2008).

39. A.S. Khanna, Introduction to High Temperature Oxidation and Corrosion (ASM International, 2002).

40. M. Soustelle, Cinétique hétérogène : Mécanismes et réactivité, vol. 3 (Hermes-Lavoisier, 2006).

41. G.J Ackland and A.P. Jones Phys. Rev. B 73, 054104 (2006).

42. H. Tsuzuki, P.S. Branicio, J.P. Rino, Comput. Phys. Comm. 177, 518 (2007).

43. I. Levine and D. Brandon, J. Am. Ceram. Soc. 81, 1995 (1998). 


\section{Figure Captions}

Fig. 1. (a) Bulk polycrystalline aluminum sample composed of 62969 atoms. The grey light atoms correspond to the grains and the dark grey to the grain boundaries. (b) Schematic representation of the simulation box which contains aluminum slab and $\mathrm{O}_{2}$ gas. The arrows indicate the loading direction (uniaxial deformation, $+7 \%$ ).

Fig. 2. (a) Evolution of the number of oxygen atoms consumed by the oxidation process and (b) of the thickness of the oxide film in function of time, temperature and applied strain.

Fig. 3. Oxidation time as a function of the number of oxygen atoms. The symbols are the results from the simulations. The straight lines are the fit with the comprehensive logarithmic law (straight line) for each oxidation condition.

Fig. 4. Temperature of the oxide film formed as a function of time for different oxidation temperature $(300,600$ and $750 \mathrm{~K})$ and straining conditions $(+7 \%)$.

Fig. 5. Pair distribution function, $\mathrm{g}(\mathrm{r})$, for the Al-O inter-atomic distances in the middle part of the oxide films. 


\begin{tabular}{|c|c|c|c|c|}
\hline & $\begin{array}{c}\mathrm{K}_{1} \\
\text { atoms.nm }\end{array} .^{-1} \mathrm{ps}^{-1}$ & $\begin{array}{c}\mathrm{D} \\
\mathrm{ps}^{-1}\end{array}$ & $\begin{array}{c}\mathrm{K}_{\log } \\
\text { atoms.nm }\end{array}$ & $\mathrm{E}$ \\
\hline $300 \mathrm{~K}$ & 0.0634 & 0.0209 & 57.4320 & 0.00932 \\
\hline $600 \mathrm{~K}$ & 0.0655 & 0.0197 & 62.2611 & 0.02868 \\
\hline $750 \mathrm{~K}$ & 0.0634 & 0.0133 & 85.6410 & 0.4500 \\
\hline $600 \mathrm{~K}-+7 \%$ & 0.0592 & 0.0126 & 76.588 & 0.3095 \\
\hline
\end{tabular}

Table I. Parameters values of the comprehensive law according to the oxidation temperature and applied strain. 


\begin{tabular}{|c|c|c|c|c|}
\hline & $300 \mathrm{~K}$ & \multicolumn{2}{|c|}{$600 \mathrm{~K}$} & $750 \mathrm{~K}$ \\
\hline Applied strain & $0 \%$ & $0 \%$ & $\varepsilon_{X}=+7 \%$ & $0 \%$ \\
\hline $\begin{array}{l}\text { Al atomic fraction in the } \\
\text { oxide film (\%) }\end{array}$ & 0.50 & 0.53 & 0.51 & 0.52 \\
\hline $\begin{array}{l}\text { O atomic fraction in the } \\
\text { oxide film (\%) }\end{array}$ & 0.50 & 0.47 & 0.49 & 0.48 \\
\hline $\begin{array}{l}\text { Aluminum atomic density } \\
\quad\left(\text { atomes.nm }{ }^{-3}\right)\end{array}$ & 49.8 & 49.1 & 49.2 & 48.5 \\
\hline $\begin{array}{l}\text { Oxygen atomic density } \\
\quad\left(\text { atomes.nm }{ }^{-3}\right)\end{array}$ & 49.0 & 43.5 & & 44.7 \\
\hline $\begin{array}{l}\text { Total atomic density } \\
\quad\left(\text { atomes.nm }{ }^{-3}\right)\end{array}$ & 98.8 & 92.6 & 6.5 & 93.2 \\
\hline
\end{tabular}

Table II. Evolution of the atomic fractions and atomic densities in the oxide films formed at 300,600 and $750 \mathrm{~K}$, and after deformation $(+7 \%)$. 


\begin{tabular}{|c|c|c|c|c|}
\hline Conditions & $300 \mathrm{~K}$ & $600 \mathrm{~K}$ & $750 \mathrm{~K}$ & $600 \mathrm{~K}-$ Strained \\
\hline $\begin{array}{c}\text { Degree of } \\
\text { crystallinity }\end{array}$ & $31.7 \%$ & $37.6 \%$ & $41.5 \%$ & $42.5 \%$ \\
\hline
\end{tabular}

Table III. Percentage of oxygen atoms in hexagonal compact position within the oxide layer. 
FIGURE 1

(a)

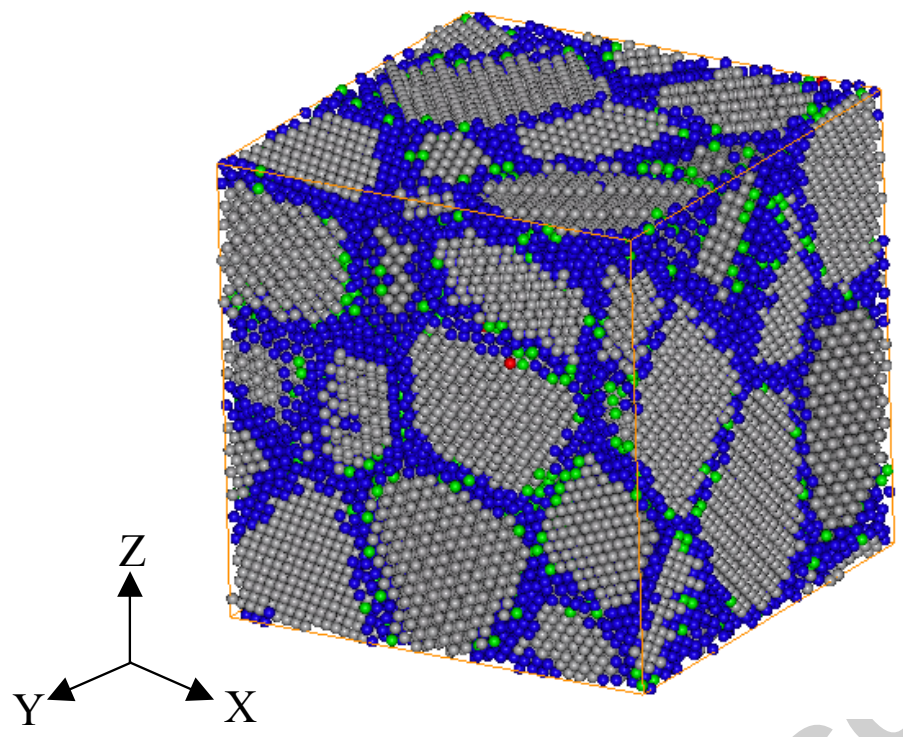

(b)

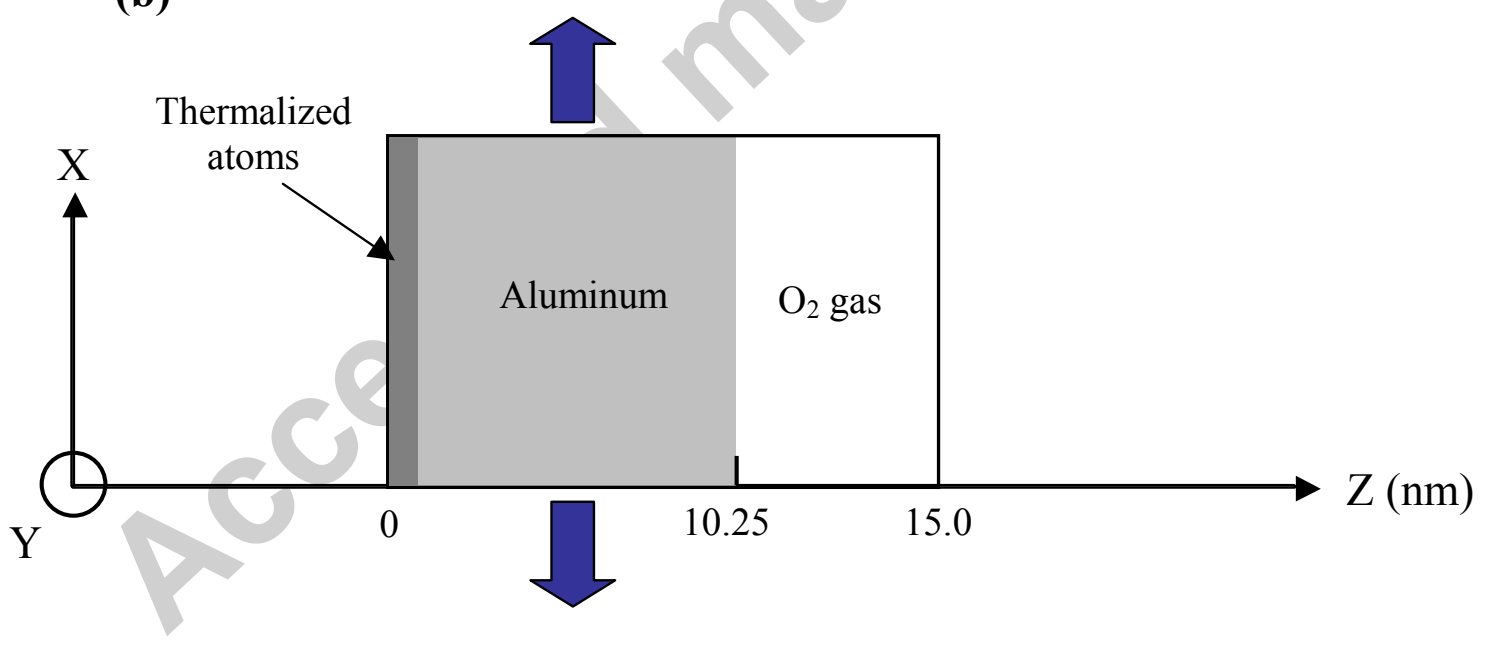


FIGURE 2

(a)

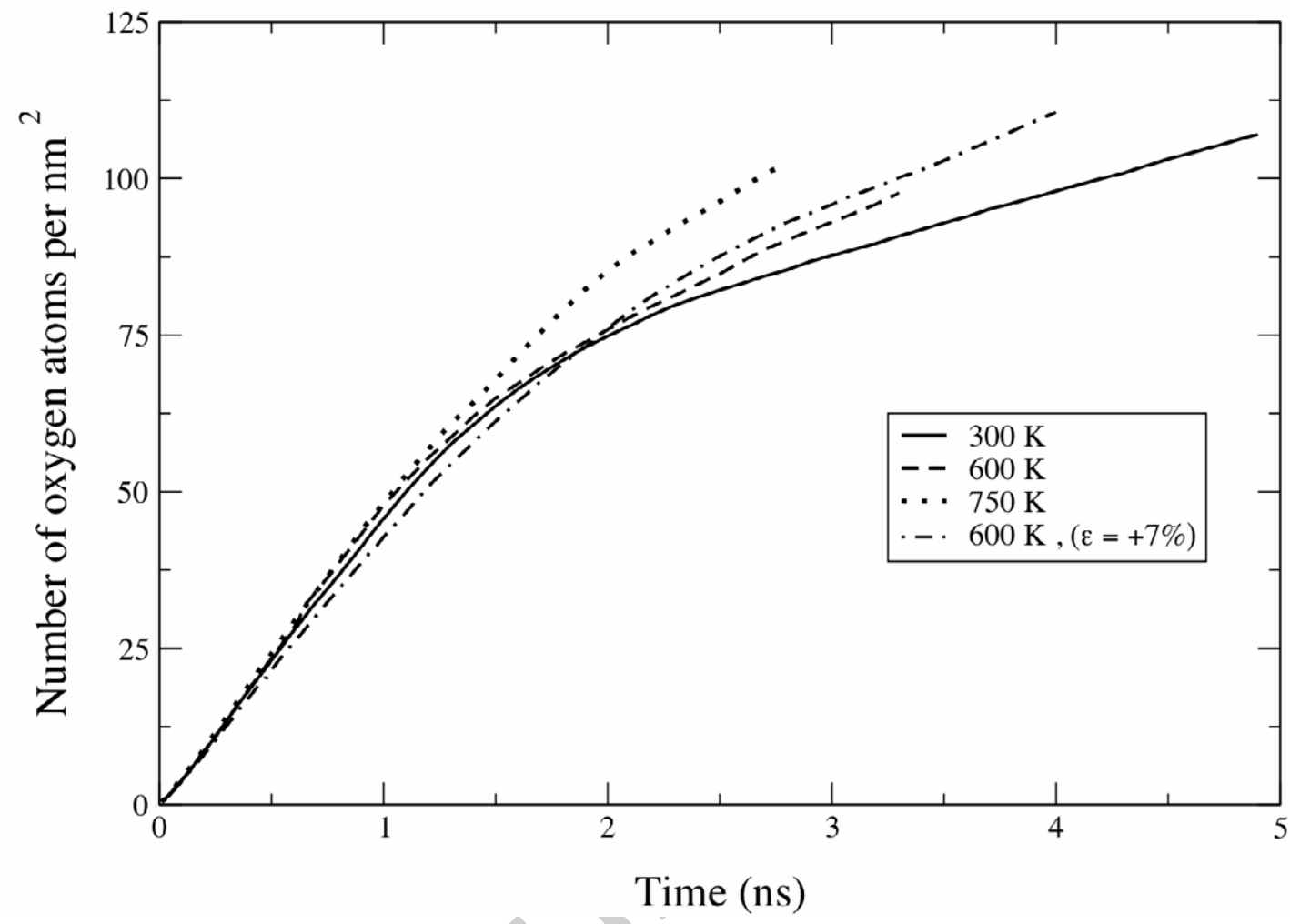

(b)

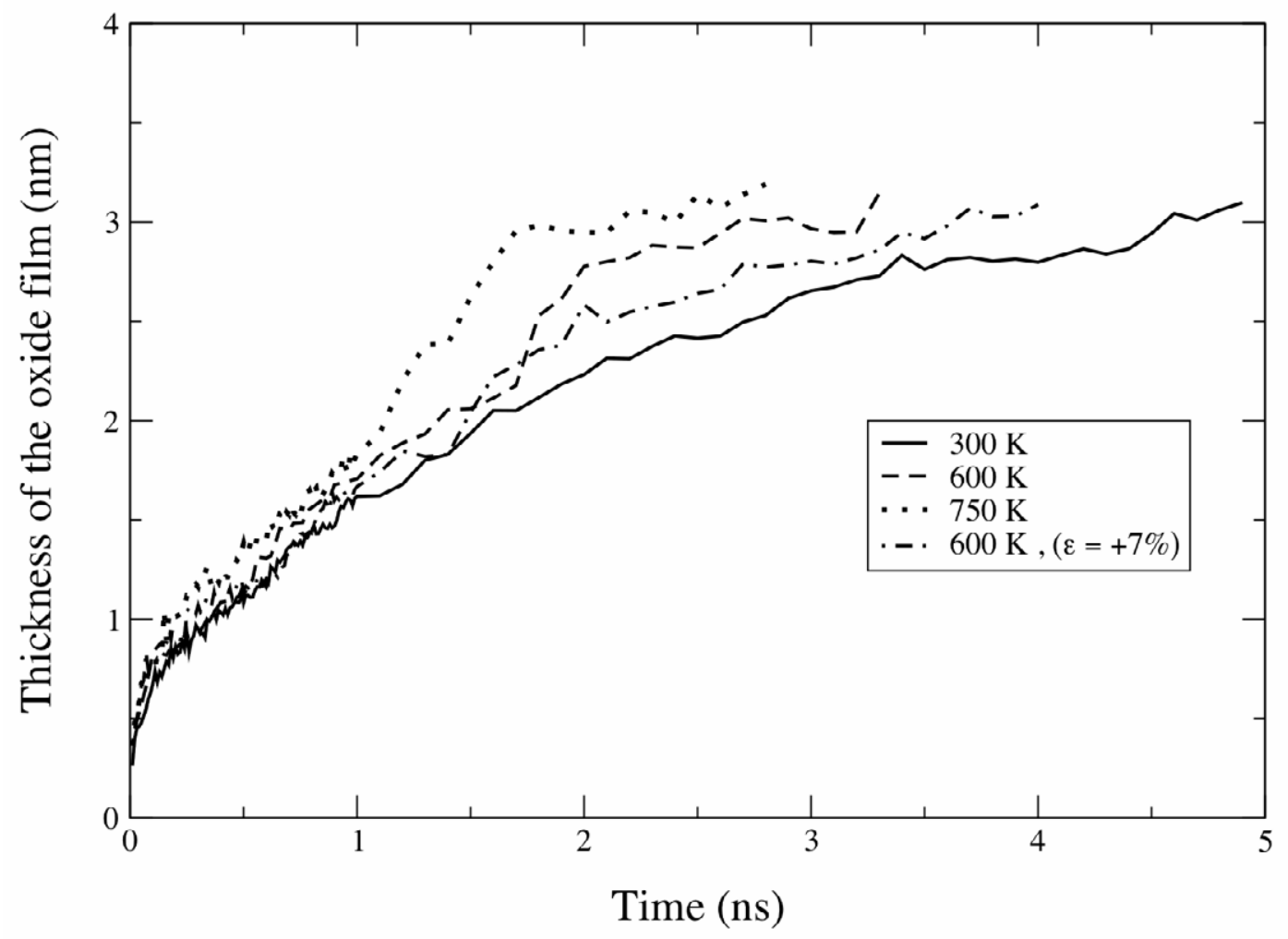


FIGURE 3

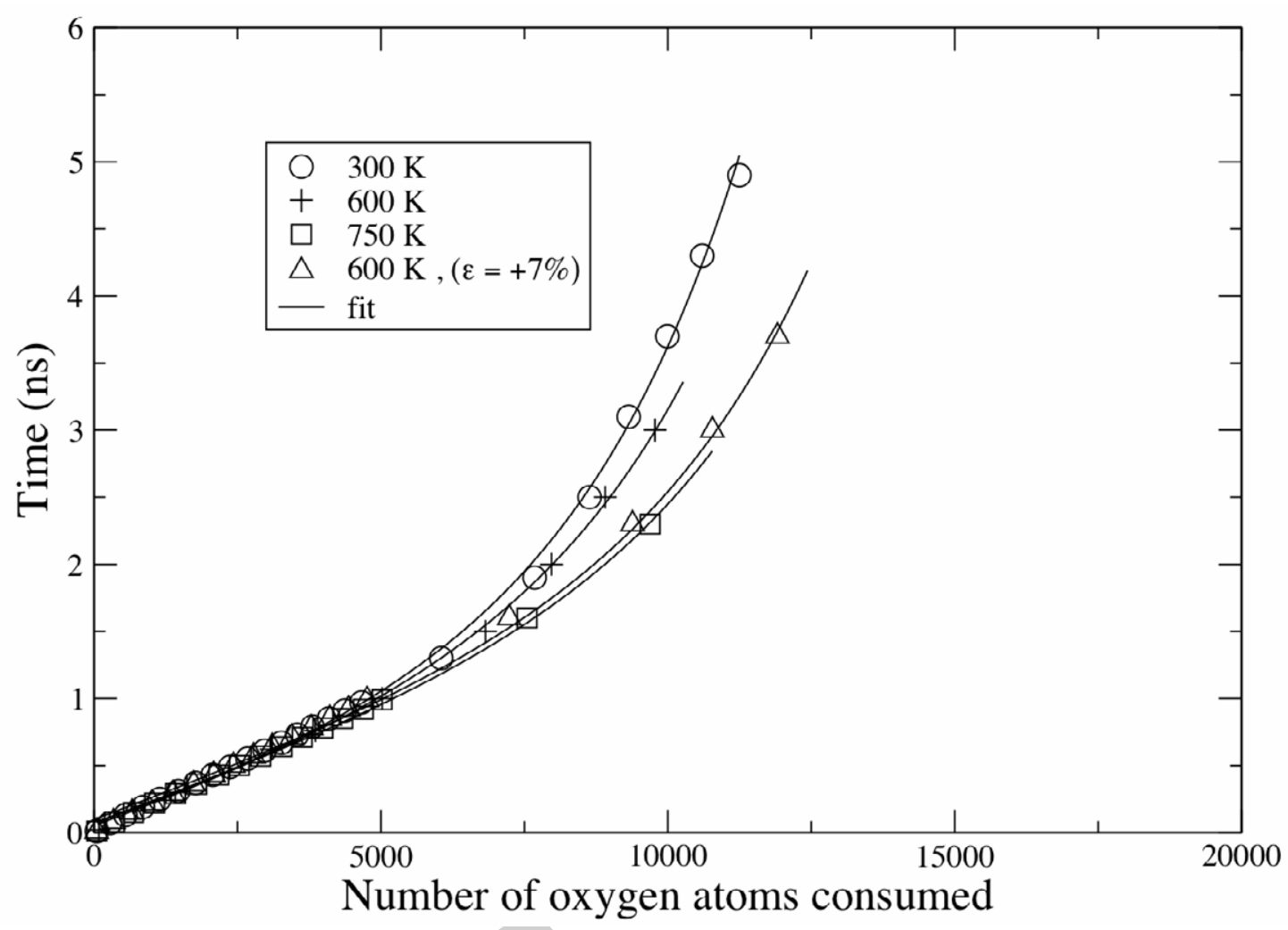


FIGURE 4

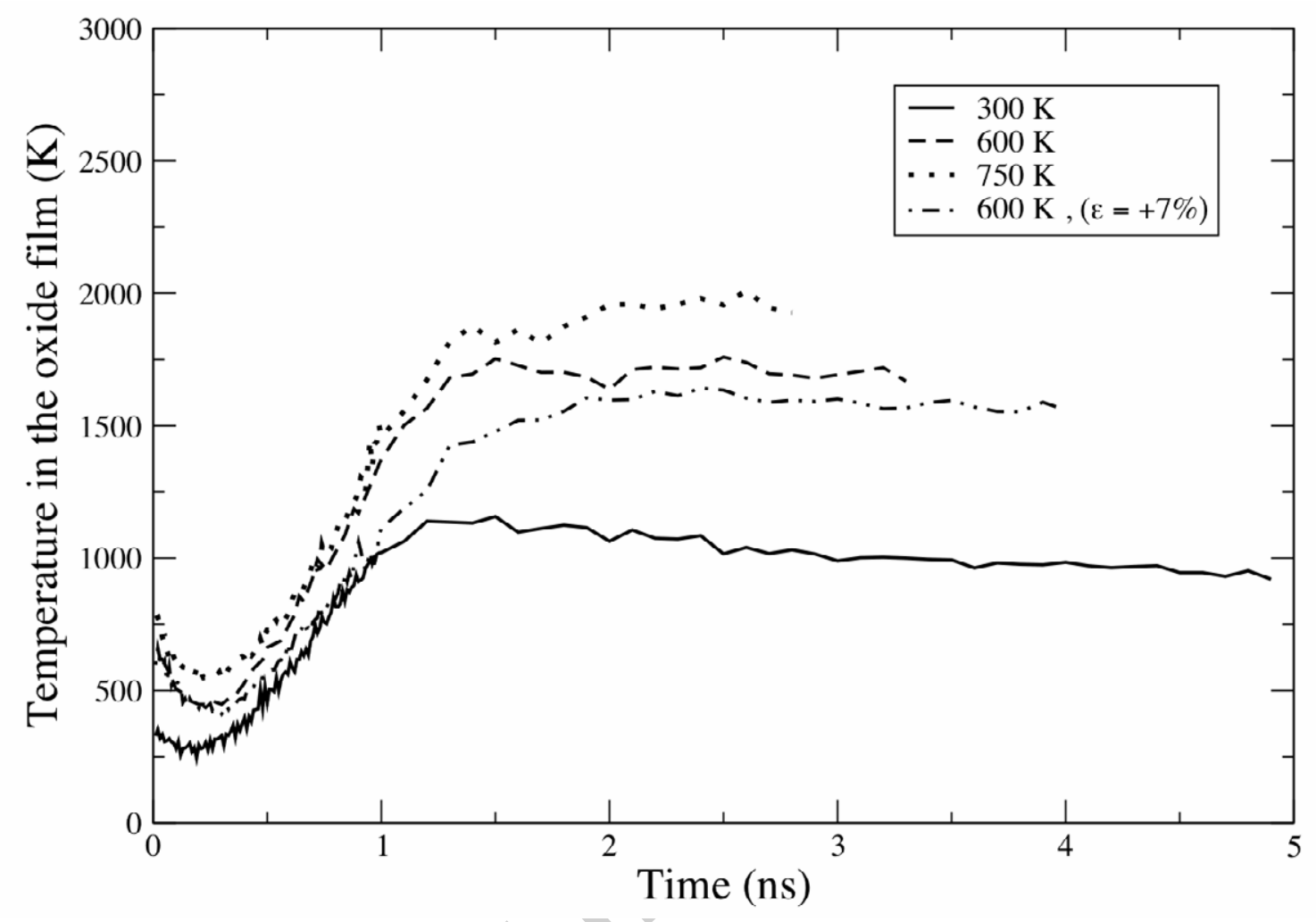


FIGURE 5

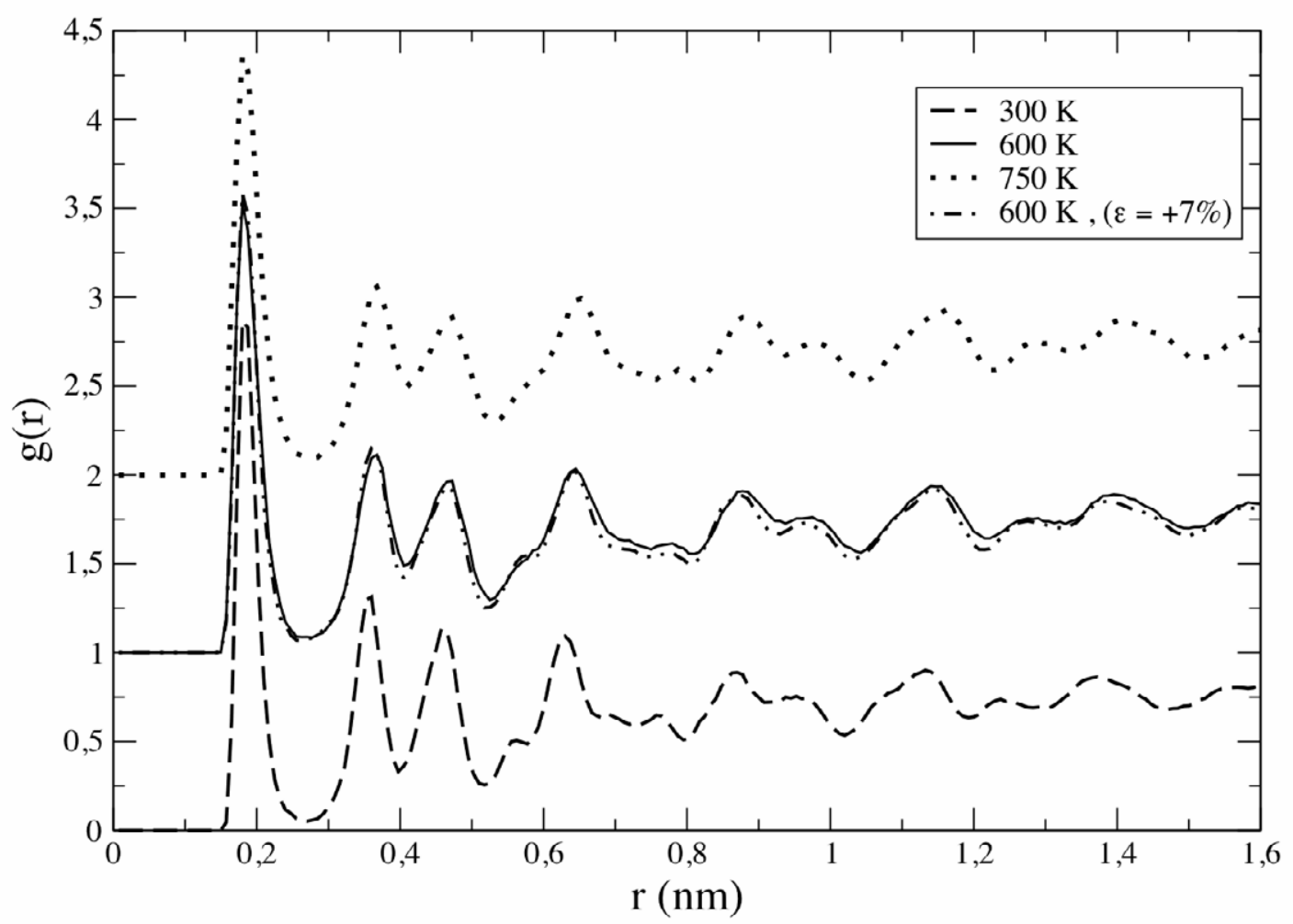

